\title{
Perceived Parenting Styles and Personality Factors - A Study
}

\author{
Savitha $\mathrm{K}^{1 *}$, Venkatachalam $\mathrm{J}^{2}$
}

\section{ABSTRACT}

The present study is aimed to assess the relation between Perceived Parenting Style and Personality Factors among Post Graduate students. Random sampling technique was used to collect the data and the sample of the study includes 185(91 male and 94 female) post graduate students. The data was collected through questionnaire method by using the Parenting Style Questionnaire (Gafoor\&Kurukkan,2014) and Big Five Personality Factor (Mc Crae\& Costa, 1991).Mean, Standard Deviation, Pearson Correlation, and t-tests were used to analyze the data and found partial relationship between Perceived Parenting Style and Personality factors; no significant difference between male and female in their personality factors; and significant difference in Perceived Parenting style of Father and Mother.

\section{Keywords: Parenting Styles \& Big Five Personality Factors}

Today many parents complain about the personality and the behavior of their children without realizing that their parenting style is the main reason behind the child's undesired behaviour. Contrary to common beliefs 'genes has nothing to do with behavior' but it's the way parents raise children that affect their personality. Parenting is a complex task that includes many specific behaviours that work individually and together to influence child's behaviour. Although specific parenting behaviours such as spanking or reading aloud may influence child development, looking at any specific behaviour in isolation may be misleading Baumrind (1967) theory of social development and parenting styles identify four parenting styles, to be exact authoritative, authoritarian, permissive and neglectful parenting.

A way of reflection between parent and child relationships is parenting and it is a complex activity that include many specific attitudes and behaviour severy single action that the parent does impact the child's personality in a way or another. Parenting can be explained in terms of two components such as parental responsiveness and demandingness (Fletcher, et al., 2008).

\footnotetext{
${ }^{1}$ Lecturer, Department of Psychology, Bhandarkars’ Arts \& Science College, KUNDAPURA, Udipi District, Karnataka State, India

${ }^{2}$ Professor, Department of Psychology, Periyar University, SALEM, Tamilnadu State, India

*Responding Author

(C) 2016, K Savitha, J Venkatachalam; licensee IJIP. This is an Open Access Research distributed under the terms of the Creative Commons Attribution License (http://creativecommons.org/licenses/by/2.0), which permits unrestricted use, distribution, and reproduction in any Medium, provided the original work is properly cited.
} 


\section{Perceived Parenting Styles and Personality Factors - A Study}

Parental demandingness is the extent to which parents set guidelines for their children, and how their discipline is based. Parental responsiveness is the emotional characteristic of parenting. Responsiveness passes on to the degree to which parents support their children and attend their children's needs. Both parenting responsive and demanding has been linked to secure attachment in children (Karavasilis, Doyle \& Markiewicz, 2003). Baumrind (1967) identified three styles: authoritative, authoritarian, and permissive with these concepts of responsiveness and demandingness in mind.

There are two main dimensions underlying parental behaviour (Maccoby\& Martin, 1983) are Parental responsiveness and Parental demandingness.

\section{Parental Responsiveness:}

Parental responsiveness (also referred to as parental warmth or supportiveness or acceptance) refers to "the extent to which parents intentionally foster individuality, self-regulation and selfassertion by being attuned, supportive and acquiescent to children special needs and demands”(Baumrind, 1971). In other words responsive is about how much or how little parents meet and respond to their children's needs!

\section{Parental Demandingness/Control:}

Parental demandingness (also referred to as behavioural control) refers to "the claims parents make on children to become integrated to the family as whole, by their maturity demands, supervision, disciplinary efforts and willingness to confront the child who disobeys” (Baumrind, 1971).Categorizing parents based on high or low on parental demandingness and responsiveness creates a quadrant of parenting styles: indulgent, authoritarian, authoritative and uninvolved (Maccoby \& Martin, 1983). Each of these parenting styles are different in naturally occurring patterns of parental values, practices and behaviours(Baumrind, 1971) and a distinct balance of responsiveness and demandingness.

Parental behaviors characterizing the four parenting styles are described in Table:

\begin{tabular}{|l|c|c|}
\hline & High Control & Low Control \\
\hline High Responsiveness & Authoritative & Permissive \\
\hline Low Responsiveness & Authoritarian & Negligent \\
\hline
\end{tabular}

Parenting style has impact on how children develop into adults, and there are certain important implications for their future success. Here are the four main parenting styles:

\section{Authoritarian parenting:}

The authoritarian parenting style is demanding and unresponsive. They engage in little mutual interaction with the children and expect them to accept adult's demands without any questions. 


\section{Perceived Parenting Styles and Personality Factors - A Study}

Failure to follow such demands usually results in punishment. It is characterized by adherence to rules, which is a dominating style and has great deal of control on the children. Authoritarian parents fail to explain the reasoning behind these rules. If asked to explain, the parent might simply reply, "Because I said so." These parents have high demands, but are not responsive to their children. Children raised by authoritarian parents tend to become authoritarian themselves, both in their interpersonal relationships and as parents. Power-assertive techniques of socialization (threads, commands, physical force, love withdrawal) used by authoritarian parents and restrain children's self-expression and independence (Zupancic et al., 2004). Authoritarian parents are inclined to set high standards and guidelines and obedience is required (Berg, 2011).

\section{Neglectful parenting:}

An uninvolved parenting style is characterized by few demands, low responsiveness and little communication. While these parents fulfill the child's basic needs, they are generally detached from their child's life. In extreme cases, these parents may even reject or neglect the needs of their children. Here, parents simply don't engage much in the parenting role. They spend little time with their children and are happy to let the TV and video games do the babysitting. Children of neglectful parents often have trouble following rules, because there have been few rules and little adherence to rules in their upbringing. Children of neglectful parents can have behaviour problems due to lack of self-control which might affect the communication skills.

\section{Permissive parenting:}

Permissive parents, sometimes referred to as indulgent parents, have very few demands to make of their children. They are characterized by attentive parents, who provide a great deal of warmth and interaction. These parents rarely discipline their children because they have relatively low expectations of maturity and self-control. This parenting style often lead to higher levels on creativity in children, but there is little self-control, few boundaries, and a sense of entitlement. They give children a high level of freedom and do not restrain their behaviours unless physical harm is involved (Rossman \& Rea, 2005).

Permissive parents expose an overly tolerant approach for socialization with responsive and undemanding parenting behaviour. These parents are nurturing and accepting, but at the same time they avoid imposing demands and controls over child's behaviour (Zupancic et al., 2004). They have little or no expectations for their children and often view their children as friends and have few limits imposed (Berg, 2011). According to Baumrind (1967), permissive parents "are more responsive than they are demanding. They are non-traditional and lenient, do not require mature behaviour, allow considerable self-regulation, and avoid confrontation".

\section{Authoritative parenting:}

Authoritative parenting is the gold standard for parenting, and is combination of demandingness and responsiveness. They make logical demands, set limits and insist on children's compliance, 


\section{Perceived Parenting Styles and Personality Factors - A Study}

whereas at the same time, they are warm, accept the children's point of view, and encourage children's participation in decision making and often seek their children's views in family considerations and decisions (Berg, 2011; Weiss \& Schwarz, 1996; Zupancic, Podlesek, \& Kavcic, 2004). This type of parent monitors and disciplines their children fairly, while being very supportive at the same time (Baumrind, 1971). Authoritative parents encourage their children to be independent, but also set limits and boundaries. Discipline is applied, but in a supportive, non-punitive way.

\section{BIG FIVE PERSONALITY FACTORS:}

\section{Extraversion}

Extraversion is marked by pronounced engagement with the external world. Extraverts enjoy being with people, are full of energy, and often experience positive emotions. They tend to be enthusiastic, action-oriented, individuals who are likely to say "Yes!" or "Let's go!" to opportunities for excitement. In groups they like to talk, assert themselves, and draw attention to themselves.

\section{Agreeableness}

Agreeableness reflects individual differences in concern with cooperation and social harmony. Agreeable individual value getting along with others. They are therefore considerate, friendly, generous, helpful, and willing to compromise their interests with others'. Agreeable people also have an optimistic view of human nature. They believe people are basically honest, decent, and trustworthy.

\section{Conscientiousness}

Conscientiousness concerns the way in which we control, regulate, and direct our impulses. Impulses are not inherently bad; occasionally time constraints require a snap decision, and acting on our first impulse can be an effective response. Also, in times of play rather than work, acting spontaneously and impulsively can be fun. Impulsive individuals can be seen by others as colorful, fun-to-be-with, and zany. Nonetheless, acting on impulse can lead to trouble in a number of ways. Some impulses are antisocial. Uncontrolled antisocial acts not only harm other members of society, but also can result in retribution toward the perpetrator of such impulsive acts. Another problem with impulsive acts is that they often produce immediate rewards but undesirable, long-term consequences.

Impulsive behavior, even when not seriously destructive, diminishes a person's effectiveness in significant ways. Acting impulsively disallows contemplating alternative courses of action, some of which would have been wiser than the impulsive choice. Impulsivity also sidetracks people during projects that require organized sequences of steps or stages. Accomplishments of an impulsive person are therefore small, scattered, and inconsistent. 


\section{Perceived Parenting Styles and Personality Factors - A Study}

The benefits of high conscientiousness are obvious. Conscientious individuals avoid trouble and achieve high levels of success through purposeful planning and persistence. They are also positively regarded by others as intelligent and reliable. On the negative side, they can be compulsive perfectionists and workaholics. Furthermore, extremely conscientious individuals might be regarded as stuffy and boring.

\section{Neuroticism}

Freud originally used the term neurosis to describe a condition marked by mental distress, emotional suffering, and an inability to cope effectively with the normal demands of life. He suggested that everyone shows some signs of neurosis, but that we differ in our degree of suffering and our specific symptoms of distress. Today neuroticism refers to the tendency to experience negative feelings.

Those who score high on Neuroticism may experience primarily one specific negative feeling such as anxiety, anger, or depression, but are likely to experience several of these emotions. People high in neuroticism are emotionally reactive. They respond emotionally to events that would not affect most people, and their reactions tend to be more intense than normal. They are more likely to interpret ordinary situations as threatening, and minor frustrations as hopelessly difficult. Their negative emotional reactions tend to persist for unusually long periods of time, which means they are often in a bad mood. These problems in emotional regulation can diminish a neurotic's ability to think clearly, make decisions, and cope effectively with stress.

At the other end of the scale, individuals who score low in neuroticism are less easily upset and are less emotionally reactive. They tend to be calm, emotionally stable, and free from persistent negative feelings. Freedom from negative feelings does not mean that low scorers experience a lot of positive feelings; frequency of positive emotions is a component of the Extraversion domain.

\section{Openness to experience}

Openness to Experience describes a dimension of cognitive style that distinguishes imaginative, creative people from down-to-earth, conventional people. Open people are intellectually curious, appreciative of art, and sensitive to beauty. They tend to be, compared to closed people, more aware of their feelings. They tend to think and act in individualistic and nonconforming ways. Intellectuals typically score high on Openness to Experience; consequently, this factor has also been called Culture or Intellect. Nonetheless, Intellect is probably best regarded as one aspect of openness to experience. Scores on Openness to Experience are only modestly related to years of education and scores on standard intelligent tests.

Another characteristic of the open cognitive style is a facility for thinking in symbols and abstractions far removed from concrete experience. Depending on the individual's specific 


\section{Perceived Parenting Styles and Personality Factors - A Study}

intellectual abilities, this symbolic cognition may take the form of mathematical, logical, or geometric thinking, artistic and metaphorical use of language, music composition or performance, or one of the many visual or performing arts. People with low scores on openness to experience tend to have narrow, common interests. They prefer the plain, straightforward, and obvious over the complex, ambiguous, and subtle. They may regard the arts and sciences with suspicion, regarding these endeavors as abstruse or of no practical use.

Fig 1: Big 5 Factors

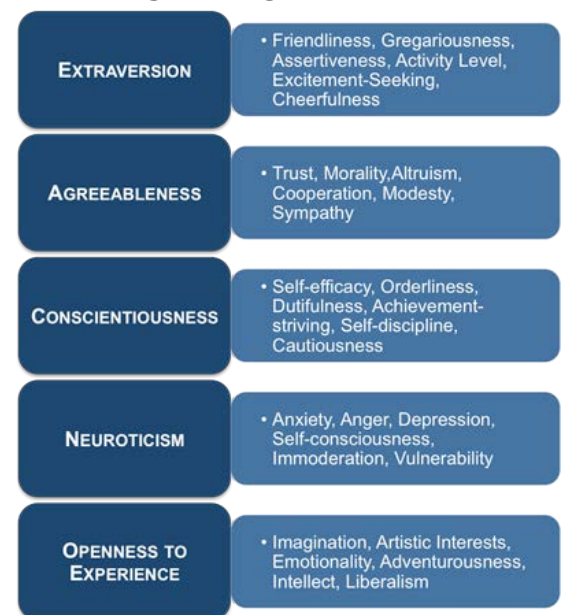

Thus the parenting styles and the personality of the parents do have immense impact on the children personality. Thus in this study, an attempt is made to see whether there is any relation between the perceived parenting style and personality factors and present below a brief review of earlier studies.

\section{Objectives of the Study:}

1. To study the Perceived Parenting Styles

2. To understand the Personality Factors

3. To see the relationship between Perceived Parenting Style and Personality Factors

4. To analyze the differences between male and female with regards to Personality Factors

5. To understand the dominant Personality Factor of the sample.

\section{Hypotheses:}

1. There would be significant relationship between Perceived Parenting Style and Personality factors

2. There would be significant difference between male and female in their personality factors

3. There would be significant difference in Perceived Parenting style of Father and Mother. 


\section{Perceived Parenting Styles and Personality Factors - A Study}

\section{Sample:}

The sample of the study include 185 post graduate students of Periyar University, Salem, India. The data was collected from 216 sample but was considered only 185 (91 male and 94 female) for the purpose of analysis. Thirty one questionnaires were not included for the analysis as they were incomplete. Simple Random sampling technique was used to collect the data.

\section{Table: 1 shows the sample distribution}

\begin{tabular}{|l|c|c|}
\hline \multicolumn{1}{|c|}{ Gender } & N & Mean age \\
\hline Male & 91 & 23 \\
\hline Female & 94 & 23 \\
\hline
\end{tabular}

\section{Data collection:}

For the purpose of the study, the data was collected through questionnaire method by using the Parenting Style Questionnaire (Gafoor\&Kurukkan,2014) and Big Five Personality Factor (Mc Crae\& Costa.1991).

\section{Assessment tools:}

\section{Parenting style}

Gafoor \& Kurukkan's (2014) Parenting Style questionnaire consists of 38 statements, measuring Perceived Parenting Style of the subjects' parents i.e., mother and father. Each statement describes how the sample perceives their mother and father while dealing with the children. The subject has to read each statement and has to respond on 5-point scale 'Very right' (5), 'Mostly right'(4), 'Sometimes right, Sometimes wrong'(3), 'Mostly wrong' (2), 'Very wrong' (1) for the mother and the father that best describes his/her mother and father in dealing with them.

The items in the scale are prepared on the basis of studies of Diana Baumrind. This has construct validity. Criterion related validity was found by correlating the scores of Scale of Parenting Style with Scale of Parenting Style developed by Usha \& Manjusha (2006). The validity coefficient was found to be 0.80 for responsiveness for and 0.76 control subscale. The reliability of the scale was established by test-retest method after an interval of one week. The test-retest coefficient of reliability of responsiveness. Sub scale was 0.81 and for control it was 0.83 .

\section{Big five personality factor:}

Big Five Personality Questionnaire of Mc Crae \& Costa (1997) which consists of 25 pairs of bipolar adjectives phrases. This tool measures the five factors of personality -Extraversion, Agreeableness, Conscientiousness, Neuroticism and Openness to experience. The subject has to indicate on numerical scale that follows, which point is generally more descriptive of him/her. If the two terms are equally descriptive, mark the midpoint. Test - retest reliability of the big five locator was found to be 0.728 . The coefficient of alpha for the five subscales was: $\mathrm{N}=0.63, \mathrm{E}=$ 
$0.77, \mathrm{O}=0.69, \mathrm{~A}=0.74$ and $\mathrm{C}=0.75$, which are reliable. It contains twenty-five pairs of bipolar adjectives phrases that correlate with the five NEO factor at 0.40 .

\section{Statistical Tests:}

For the purpose of the present study Mean, Standard Deviation, Pearson Correlation, and t-test were used and the data were analyzed using SPSS.

\section{RESULTS \& DISCUSSION}

In this chapter the result of the study are presented, analyzed and discussed. The analysis has been undertaken to verify the hypotheses which are presented in the previous chapter.

Table 1: Correlation between Perceived Parenting style and Personality Factors

\begin{tabular}{|c|c|c|c|c|c|c|}
\hline & MC & MR & FC & FR & PR & PC \\
\hline Extraversion & 0.091 & 0.115 & 0.071 & 0.022 & 0.072 & $0.091^{\mathrm{NS}}$ \\
\hline Agreeableness & 0.098 & 0.121 & 0.089 & 0.022 & 0.075 & $0.104^{\mathrm{NS}}$ \\
\hline Conscientiousness & 0.066 & 0.060 & 0.048 & 0.051 & 0.060 & $0.067^{\mathrm{NS}}$ \\
\hline Neuroticism & $0.218^{* *}$ & $0.231^{* *}$ & 0.091 & $0.175^{*}$ & $0.218^{* *}$ & $0.155^{*}$ \\
\hline Openness & $0.248^{* *}$ & $0.211^{* *}$ & $0.156^{*}$ & $0.174^{*}$ & $0.208^{* *}$ & $0.209^{* *}$ \\
\hline MC-Mother Control; MR-Mother Responsive; FC-Father Control; FR-Father Responsive; PC- \\
Parent Control; PR-Parent Responsive \\
\hline
\end{tabular}

* Significant at $0.05 ; * *$ significant at 0.01 level; ${ }^{\text {NS }}$ Not Significant

Table1 shows the r-scores of Perceived Parenting Style and Personality Factors among PG students. From the table, it can be observed that all the dimensions (except for father control and neuroticism) of perceived parenting styles viz. Mother Control and Responsiveness, Father Control and Responsiveness and Parental Control and Responsiveness are positively correlated with neuroticism and openness dimensions of personality factors. Hence, the $\mathbf{H}_{\mathbf{1}}$ is partially accepted.

However, Maddahi and Samadzadeh (2010) showed that three personality traits, namely agreeableness, extraversion and openness has a positive relationship with authoritarian and permissive parenting style and has a negative relationship with authoritative parenting style and conscientiousness personality trait has a positive relationship with authoritative and authoritarian parenting styles and a negative relationship with permissiveness parenting style. Therefore, it can be generally concluded that parent's parenting styles and the way they interact with their children can be effective on evolving children's personality traits and the parents who support authoritative parenting styles contribute to evolving positive characteristics such as agreeableness, extraversion and openness in their children. 
Perceived Parenting Styles and Personality Factors - A Study

Table 2: Difference in personality factors based on the gender

\begin{tabular}{|c|c|c|c|c|c|}
\hline \multirow{2}{*}{ Personality Factors } & \multicolumn{2}{|c|}{ Male (N=91) } & \multicolumn{2}{c|}{ Female (N=94) } & \multirow{2}{*}{ “t” value } \\
\cline { 2 - 5 } & $\mathbf{M}$ & $\mathbf{S D}$ & $\mathbf{M}$ & $\mathbf{S D}$ & \\
\hline Extraversion & 14.89 & 3.24 & 14.46 & 2.90 & $0.93^{\text {NS }}$ \\
\hline Agreeableness & 15.48 & 3.04 & 15.19 & 3.35 & $0.61^{\text {NS }}$ \\
\hline Conscientiousness & 15.75 & 3.07 & 14.96 & 2.81 & $1.82^{\text {NS }}$ \\
\hline Neuroticism & 16.89 & 3.03 & 16.98 & 2.96 & $0.22^{\text {NS }}$ \\
\hline Openness & 16.48 & 3.00 & 16.48 & 3.11 & $0.01^{\text {NS }}$ \\
\hline
\end{tabular}

Not Significant

From the table 2, it is found that ' $\mathrm{t}$ ' values are not significant for all the big five personality factors. Hence the hypothesis is not accepted. According to Bronfenbrenner (1994), macro system - that is, a cultural, or sub cultural, or a social class context in which micro systems, mesosystems, and exosystems are embedded. The macro system is really a broad, overarching ideology that dictates how children should be treated, what they should be taught, and the goals for which they should strive. There is a structural break in the socio, economic and cultural aspects of India after globalization. Everyone is influenced by similar type of information through mass media and monoculture at the macro level. Concept of gender equality is promoted across globe. Since students are in the mesosystem, there are influenced by the exosystem and macrosystem. Therefore, gender-related difference in personality may narrow down among the students. It is concluded that male and female students not differ in their personality factors. Reasons might be they are belonging to the same locality, socio-economic status and parental education.

However, the mean score of male students is high on the dimensions such as Extraversion, Agreeableness and Conscientiousness while the mean score of the female students are higher than the male counterpart in the dimension of Neuroticism and the present results are in line with the findings of Krampen, et al., (1990).

Table 3: Difference in Perceived Parenting Style based on gender

\begin{tabular}{|c|c|c|c|c|c|}
\hline \multirow{2}{*}{ Parenting style } & \multicolumn{2}{|c|}{ Male (N=91) } & \multicolumn{2}{c|}{ Female (N=94) } & \multirow{2}{*}{ “t” value } \\
\cline { 2 - 5 } & $\mathbf{M}$ & $\mathbf{S D}$ & $\mathbf{M}$ & $\mathbf{S D}$ & “t \\
\hline MC & 68.95 & 11.93 & 73.36 & 10.68 & $2.65^{*}$ \\
\hline MR & 71.37 & 12.85 & 76.35 & 10.09 & $2.93^{*}$ \\
\hline FR & 66.15 & 12.74 & 73.00 & 11.85 & $3.79^{*}$ \\
\hline FC & 65.47 & 11.65 & 70.02 & 12.00 & $2.61^{*}$ \\
\hline PC & 127.17 & 20.69 & 135.78 & 20.35 & $2.85^{*}$ \\
\hline PR & 137.52 & 23.85 & 149.35 & 19.78 & $3.68^{*}$ \\
\hline
\end{tabular}

* Significant at 0.05 and $* *$ significant at 0.01 level 


\section{Perceived Parenting Styles and Personality Factors - A Study}

Table 3 shows the results of differences between male and female on perceived parenting style. It is found that ' $t$ ' values are significant for all the dimensions of parenting style. Hence $\mathbf{H}_{\mathbf{3}}$ is accepted.

The above results are similar to the findings of Mestre, et al., (2001). Larson and Richards (1994) suggested that fathers and mothers have unique and different relationships with children depending on the gender of their offspring. Ecological theory would contend that the variations in parental behavior toward children are based largely on cultural norms and expectations regarding paternal and maternal roles. Generally speaking, females are expected to attend to the emotional and housekeeping duties of family life while males are taught to enact instrumental roles and to teach them to their children (Uba, 1994). Some researchers suggest that because of different societal expectations of gender roles, mothers typically spend more time with adolescents, are involved in a wider range of activities with them, and are more likely than fathers to provide care-giving (Holmbeck et al., 1995). Conversely, fathers tend to spend more time engaged in leisure and instrumental activities with adolescents (Holmbeck et al., 1995). These interactions generally result in more mutuality, closeness, and support within the motherchild as opposed to the father-child relationship during the adolescent period (Collins \& Russell, 1991). Laible and Carlo (2004) argue that because of the different relationships that mothers and fathers have with their children, warmth/support and control from mothers and fathers may have different effects on perception of adolescent functioning. Hence, it can be inferred that the females will have higher score on the perception of parenting style than their male counterpart. Conclusion:

Personality is a dynamic and organized set of characteristics possessed by a person that uniquely influences their environment, cognitions, emotions, motivations and behavioral science in various situations. It refers to the pattern of thoughts, feelings, social adjustments, and behaviors consistently exhibited over time that strongly influences one's expectations, self-perceptions, values and attitudes. It also predicts human reactions to other people, problems and stress. Studies revealed relationship between some parenting styles and psychological, behavioral problem, self-esteem and academic performance among children and adolescents. There appears to be solid evidence illustrating the influence parenting behaviors and parenting styles on their children and in the present study an attempt was made to examine the relationship between Perceived Parenting Styles and Personality factors, and found partial relationship between Perceived Parenting Style and Personality factors; no significant difference between male and female in their personality factors; and significant difference in Perceived Parenting style of Father and Mother.

\section{Scope for the further study:}

- $\quad$ Studies can be conducted by large number of samples. 


\section{Perceived Parenting Styles and Personality Factors - A Study}

- Instead of studying about personality alone it can be developed by comparing other variables like emotional intelligence, assertiveness, personal growth initiatives, self-esteem, intelligence, locus of control.

- Studies can also be carried out to understand the various demographic variables and its impact on the personality factors and parenting styles.

\section{Delimitation:}

- Being the sample is very small and only limited to small portion total population of the university, the findings of the present study cannot be generalized.

- In the present study only the parental (mother \& father) control and responsiveness was studied but not the types of parenting styles.

\section{Acknowledgments}

The author appreciates all those who participated in the study and helped to facilitate the research process.

\section{Conflict of Interests}

The author declared no conflict of interests.

\section{REFERENCES}

Baumrind, D. (1967). Child care practices anteceding three patterns of preschool behavior. Genetic Psychology Monographs, 75(1), 43-88.

Baumrind, D. (1971). Current patterns of parental authority. Developmental Psychology Monographs, 4, 1-103.

Berg, B. (2011). The Effects of Parenting Styles on a Preschool Aged Child's Social Emotional Development. The Graduate School, University of Wisconsin-Stout.

Collins, W. A., \& Russell, G. (1991). Mother-child and father-child relationships in middle childhood and adolescence: A developmental analysis. Developmental Review, 11(2), 99-136.

Gafoor, A. K., \& Kurukkan A., (2014). Construction and Validation of Scale of Parenting Style. Guru Journal of Behavioral and Social Sciences, 2(4), 315-323.

Karavasilis, L., Doyle, A. B., \& Markiewicz, D. (2003). Associations between parenting style and attachment to mother in middle childhood and adolescence. International Journal of Behavioral Development, 27(2), 153-164.

Krampen, G., Effertz, B., Jostock, U., \& Müller, B. (1990). Gender differences in personality: Biological and/or Psychological? European Journal of Personality, 4(4), 303-317.

Laible, D. J., \& Carlo, G. (2004). The differential relations of maternal and paternal support and control to adolescent social competence, self-worth, and sympathy. Journal of Adolescent Research, 19(6), 759-782.

Larson, R. W., \& Richards, M. H. (1994). Family emotions: Do young adolescents and their parents experience the same states? Journal of Research on Adolescence, 4(4), 567-583. 


\section{Perceived Parenting Styles and Personality Factors - A Study}

Maccoby, E. E., \& Martin, J. A. (1983). Socialization in the context of the family: Parent-child interaction. Handbook of child psychology: formerly Carmichael's Manual of child psychology/Paul H. Mussen, editor.

Maddahi, M. E., Javidi, N., Samadzadeh, M., \&Amini, M. (2012). The study of relationship between parentingstyles and personality dimensions in sample of college students. Indian Journal of Science and Technology, 5(9), 3332-3336.

McCrae, R. R., \& Costa, P. T., Jr. (1991). Adding Liebe und Arbeit: The full five-factor model and well-being. Personality and Social Psychology Bulletin, 17, 227-232.

Rossman, B. R., \& Rea, J. G. (2005). The relation of parenting styles and inconsistencies to adaptive functioning for children in conflictual and violent families. Journal of Family Violence, 20(5), 261-277.

Usha, P., \& Manjusha, V. P. (2006).Influence of Parenting Styles of Working and Non-Working Mothers on Mental Health and Achievement in Biology of Secondary School Pupils. Unpublished doctoral dissertation, University of Calicut, India.

Weiss, L. H., \& Schwarz, J. C. (1996). The relationships between parenting types and older adolescents' personality, academic achievement, adjustment and use. Child Development, 67(5), 2101-2114.

Zupančič, M., Podlesek, A., \& Kavčič, T. (2004). Parental child-care practices of Slovenian preschoolers' mothers and fathers: The Family Environment Questionnaire. Psihološkaobzorja, 13 (3), 7-26.

How to cite this article: K Savitha, J Venkatachalam (2016), Perceived Parenting Styles and Personality Factors - A Study, International Journal of Indian Psychology, Volume 3, Issue 4, No. 66, ISSN 2348-5396 (e), ISSN: 2349-3429 (p), DIP:18.01.155/20160304, ISBN: 978-1-36539396-9 